\title{
Analysis of Screwed Shaft Failure using the Process Simulation of Loaded Torsion
}

\author{
Vita Mustika ${ }^{a}$ Agus Trionob ${ }^{b}$ R. Koekoeh K. Wibowo \\ a,b,c Postgraduate Program of Mechanical Engineering, The University of Jember-Indonesia \\ e-mail: vitamustika@ymail.com, agus.triono@unej.ac.id,
}

\begin{abstract}
The paper present the result of the study on the use of simulation software of ANSYS R15.0 version in attempt to simulate the load which is working on a screwed shaft of a shaping machine. This shaft was broken down during normal working and within limit of its life time. Therefore, the simulation aims to find out the cause of the failure by analyzing static and torsion load using von Misses criterion. In order to simulate the load, the mechanical properties and chemical composition of the shaft were used as the input for modeling. The shaft is made of medium carbon steel of $S 45 \mathrm{C}$ in round shape. The finite element method (FEM) was used for analyzing. The modeling was started with a 3D redrafting the real dimension of the shaft in a computer aided design (CAD) model, then imported to the ANSYS system into FEM format. The mechanical and physical properties of the material was entered as the engineering data. Meshing was made to divide the component into several small elements. A combination of static and torsion load was applied to the shaft with a fixed position. The simulation results shown that von mises stress of $4.546 \mathrm{MPa}$ was achieved. While, the first principal stress of $4.518 \mathrm{MPa}$, the third principal stress of 0.538 $\mathrm{MPa}$. Other result revealed that the displacement was $0.001602 \mathrm{~mm}$. Simulation also indicate that failure occurs at the slot a place where the pin was inserted to lock between the shaft and the bevel gear. The result is in accordance with the real failure of the shaft. To conclude, the ANSYS with FEM modeling has succeeded to simulate the failure of the screwed shaft.
\end{abstract}

\section{INTRODUCTION}

Developments in the field of design and manufacturing of construction machinery have led to continuous testing of materials with various methods. Although all types of material on the market have undergone a process of testing the strength and mechanical behavior, it turns out there is still a lot of information needed by designers and technicians that have not been maximally fulfilled. One of the things that still needs to be done is research in obtaining dynamic and static material behavior in various loading conditions.

The screw shaft, as depicted in Figure 1, is one part of the engine component that is experiencing dynamic load voltage fluctuations will occur. When fluctuations that occur repeatedly as often as possible, there will be a failure, even though the maximum stress that occurs is still smaller than the static strength of the screw shaft material.

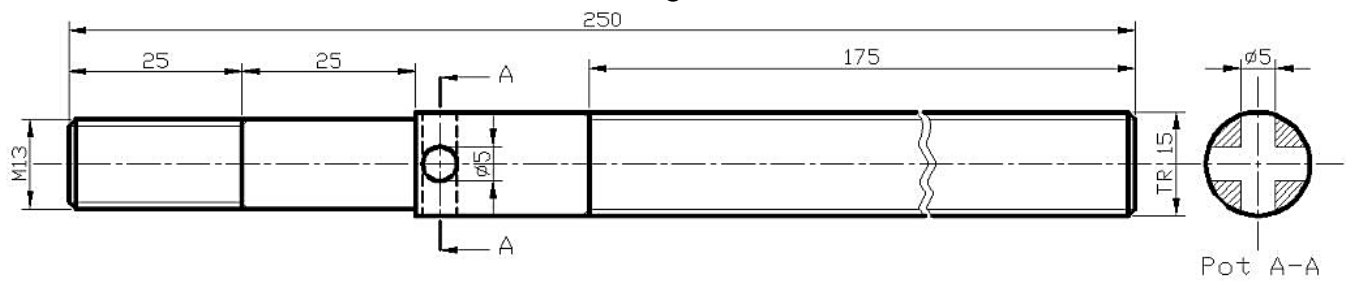

Figure 1. A Screwed Shaft

The failure of a material is inseparable from the structural characteristics it has. Screw shaft failure occurs at points where there is a stress concentration, where the source of the stress concentration in the engine element can be a notch, groove, hole, thread, peg and others as shown in Figure 2. 


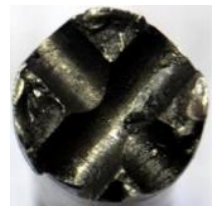

Figure 2. Screwed Shaft Failure

\section{LITERATURE REVIEW}

Torsionally loaded shafts are among the most commonly used structures in engineering, serves primarily to transmit torsion. These shafts are almost always hollow and circular in cross section, transmitting power from the transmission to the differential joint at which the rotation is diverted to the drive wheels [1-2]. Many shaft are manufactured from carbon steel [3] and sometimes is added with other alloy [4]. Also, the shaft goes into heat treatment to improve its prperties [5-8]. As in the case of the shaft length regulating drive shaft, it is important to note design methods for such structures are purely for inherent uses. However, we study they are here too because they illustrate the role of shear stress and strain.

Not all deformation is elongational or compressive, and we need to extend our concept of strain to include "shearing," or "distortional," effects. To illustrate the nature of shearing distortions, first consider a square grid inscribed on a tensile specimen as depicted in Fig. 2(a). Upon uniaxial loading, the grid would be deformed so as to increase the length of the lines in the tensile loading direction and contract the lines perpendicular to the loading direction. However, the lines remain perpendicular to one another. These are termed normal strains, since planes normal to the loading direction are moving apart.

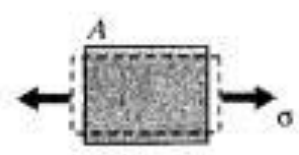

(a)

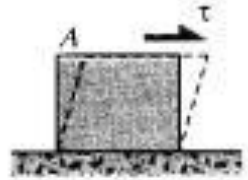

(b)

Figure 3. (a) Normal and (b) shearing deformations

Now consider the case illustrated in Fig. 3 (b), in which the load $P$ is applied transversely to the specimen. Here the horizontal lines tend to slide relative to one another, with line lengths of the originally square grid remaining unchanged. The vertical lines tilt to accommodate this motion, so the originally right angles between the lines are distorted. Such a loading is termed direct shear. Analogously to our definition of normal stress as force per unit area, or $\sigma=P / A$, we write the shear stress $\mathrm{T}$ as

$\tau=P / A$

This expression is identical to the expression for normal stress, but the different symbol $\mathrm{T}$ reminds us that the loading is transverse rather than extensional.

\section{Methodology and Analysis}

The computer simulation was executed using ANSYS software based on Finite Element Analysis. The geometry of shaft was given in Figure 1, and the material and its properties was given in the following. Screwed shaft with the type of steel construction machinery, the symbol S $30 \mathrm{C}$ with the following specifications: Tensile strength $48 \mathrm{~kg} /$ $\mathrm{mm} 2$, elongation limit $29 \mathrm{~kg} / \mathrm{mm} 2$, Hardness $(\mathrm{Hs}) 137-197 \mathrm{~kg} / \mathrm{mm} 2$, Chemical Elements $(\%): \mathrm{C}=0.27-0.33, \mathrm{Si}=0.15-0.35, \mathrm{Mn}=0.60-0.90, \mathrm{P}=0.030, \mathrm{~S}=0.035$. The material is assumed as billinear isotropic hardening.

Research Steps:

1. Study the application of case study

2. Generate 3D CAD model using autodesk inventor 2018 software (Figure5)

3. To do the meshing of component

4. To do static analysis using ANSYS

5. Modify the material or geometry and conduct the analysis on same

6. Recommend Solution

7. Conclusion

The research steps was given in Figure 4 as follows: 


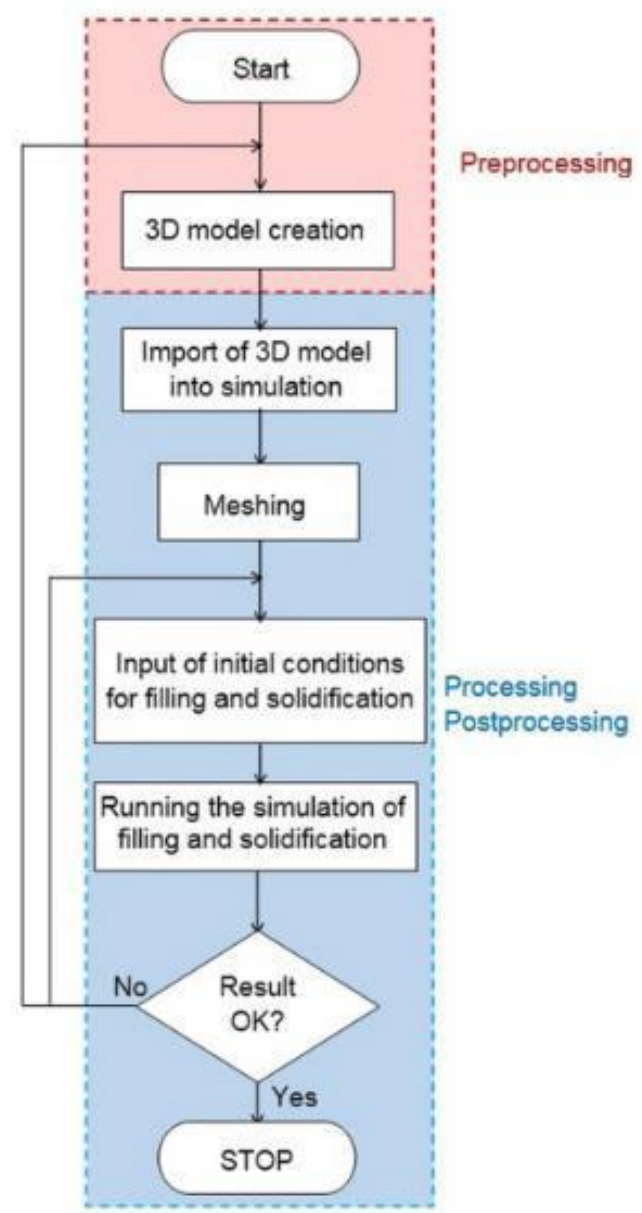

Figure 4. Flowchart

\section{Results AND Discussion}

From the computer simulation, it can be obtained that the stress analysis report of physical and material of screwed shaft failure of the current model are appeared in table below:

\begin{tabular}{ll}
\multicolumn{1}{c}{ Mable 1. Physical } \\
\hline Density & \multicolumn{1}{c}{ Steel, Mild } \\
Mass & $0.283599 \mathrm{lb}$ mass $/ \mathrm{in}^{3}$ \\
Area & $0.650741 \mathrm{lb}$ mass \\
Volume & $15354.6 \mathrm{~mm}^{2}$ \\
Center of Gravity & $37601.4 \mathrm{~mm}^{3}$ \\
& $\mathrm{x}=-0.00339388 \mathrm{~mm}$ \\
& $\mathrm{y}=0.00352927$ \\
$\mathrm{z}=122.08 \mathrm{~mm}$ \\
\hline
\end{tabular}

\begin{tabular}{cll}
\multicolumn{3}{c}{ Table 2. Material } \\
\hline Name & \multicolumn{1}{c}{ Steel, Mild } & \\
\hline General & Mass Density & $0.283599 \mathrm{lbmass} / \mathrm{in}^{3}$ \\
& Yield Strength & $30022.8 \mathrm{psi}$ \\
Stress & Ultimate Tensile Strength & $50038 \mathrm{psi}$ \\
& Young's Modulus & $31908.3 \mathrm{ksi}$ \\
& Poisson's Ratio & $0.275 \mathrm{ul}$ \\
& Shear Modulus & $12513.1 \mathrm{ksi}$ \\
\hline
\end{tabular}




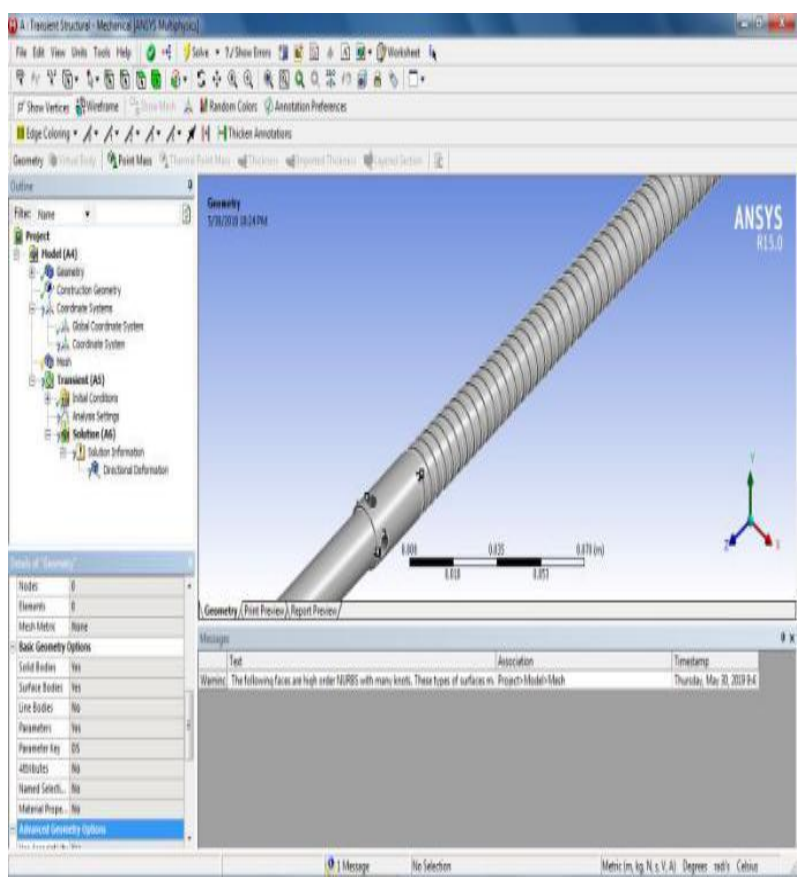

Figure 5. Modelling

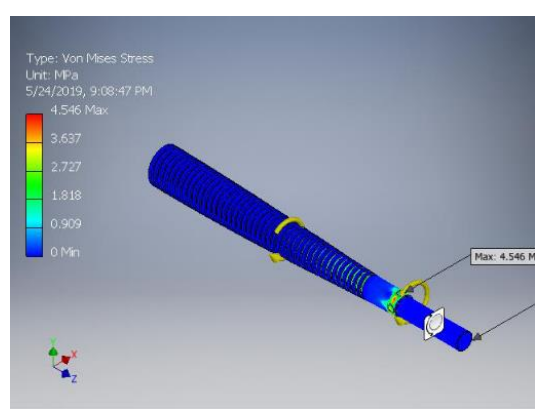

(a)

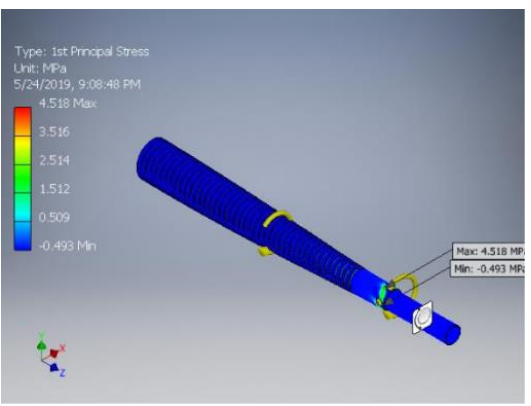

(b)

The ANSYS examination demonstrates that von Mises stress of $4.546 \mathrm{MPa}$ was achieved as given in Figure $5 \mathrm{a}$. While, the first principal stress of $4.518 \mathrm{MPa}$, the third principal stress of $0.538 \mathrm{MPa}$ as shown in Figure $5 \mathrm{~b}$. Other result revealed that the displacement was $0.001602 \mathrm{~mm}$. All principal stress located near the pen hole so that caution must be given to the area during its service life.

\section{CONCLUSIONS}

From the simulation, it can be summarized that for screwed shaft, the failure may occur because of maximum stress zones were located near the pen hole and overlap the crack origins caused by high torque of the shaft. This conditions may leads to fatigue fracture of screwed shaft.

\section{ACKNOWLEDGMENTS}

I express my sincere thanks with deep sense of gratitude of my guide Mahros Darsin, S.T. M.Sc., Ph.D. (Associate professor in Manufacturing Engineering and Materials Science) for his encouragement, valuable suggestions, guidance and help throughout the preparation of this paper. I would like to express my deepest appreciation towards Dr. Gaguk Jatisukamto, S.T., M.T. (Senior lecturer in Mechanical Engineering Design and Failure Analysis) whose valuable guidance supported in preparing the project. I would also like to express my respect and gratitude to the head of the postgraduate department Dr. Nasrul Ilminnafik, S.T., M.T. (Senior lecturer in Renewable Energy) for giving this opportunity to prepare a project report.

\section{REFERENCES}

1. Kapadia BM. In: Doane DV, Kirkaldy JS, editors. Hardenability concepts with applications to steels. Metallurgical Society of AIME; 1978. p. 448.

2. Kapadia BM, Broun RM, Murphy WJ. The influence of nitrogen, titanium and zirconium on the boron hardenability effect in constructional steels. Trans AIME 1968; Z4Z:1698.

3. Krauss G. Steels, heat treating and processing principles. American Society for Metals; 1990.

4. Morral JE, Cameron TB. Met Trans 1977; 8A:1817.

5. Levitin VV. Phys Met Metallogr 1960; 10:130.

6. Borisove VT et al. Phys Met Metallogr 1964; 17:80.

7. Mavropoulos LT, Jonas JJ. Can Metall Quart 1988; 27:235.

8. Watanabe S, Otani H, Kunitake T. Trans ISIJ 1983; 23:31. 